\title{
Dermatoscopic findings of pigmented purpuric dermatosis*
}

\author{
Dilek Biyik Ozkaya ${ }^{1}$ \\ Ozlem Su${ }^{1}$ \\ Anil Gulsel Bahali ${ }^{1}$ \\ Cuyan Demirkesen ${ }^{2}$
}

\author{
Nazan Emiroglu ${ }^{1}$ \\ Fatma Pelin Cengiz ${ }^{1}$ \\ Pelin Yildiz ${ }^{1}$ \\ Nahide Onsun ${ }^{1}$
}

DOI: http://dx.doi.org/10.1590/abd1806-4841.20165124

\begin{abstract}
BACKGROUND: Pigmented purpuric dermatosis is a chronic skin disorder of unknown aetiology characterised by symmetrical petechial and pigmented macules, often confined to the lower limbs. The aetiology of pigmented purpuric dermatosis is unknown. Dermatoscopy is a non-invasive diagnostic technique that allows the visualisation of morphological features invisible to the naked eye; it combines a method that renders the corneal layer of the skin translucent with an optical system that magnifies the image projected onto the retina.

Овлестіves: The aim of this study is to investigate the dermatoscopic findings of pigmented purpuric dermatosis.

Methods: This study enrolled patients diagnosed histopathologically with pigmented purpuric dermatosis who had dermatoscopic records. We reviewed the dermatoscopic images of PPD patients who attended the outpatient clinic in the Istanbul Dermatovenereology Department at the Bezmialem Vakıf University Medical Faculty.

RESULTS: Dermatoscopy showed: coppery-red pigmentation $(97 \%, \mathrm{n}=31)$ in the background, a brown network $(34 \%, \mathrm{n}=11)$, linear vessels $(22 \%, \mathrm{n}=7)$, round to oval red dots, globules, and patches $(69 \%, \mathrm{n}=22 ; 75 \%, \mathrm{n}=24 ; 34 \%, \mathrm{n}=11 ;$ respectively), brown globules $(26 \%, \mathrm{n}=8)$ and dots $(53 \%, \mathrm{n}=17)$, linear brown lines $(22 \%, \mathrm{n}=7)$, and follicular openings $(13 \%, \mathrm{n}=4)$. Conclusion: To our knowledge, this is the first study to report the dermatoscopy of pigmented purpuric dermatosis. In our opinion, dermatoscopy can be useful in the diagnosis of pigmented purpuric dermatosis.
\end{abstract}

Keywords: Skin Diseases; Purpura; Diagnostic Imaging

\section{INTRODUCTION}

Pigmented purpuric dermatosis (PPD) is a chronic skin disorder of unknown aetiology characterised by symmetrical petechial and pigmented macules, often confined to the lower limbs. ${ }^{1}$ It is identified by extravasation of erythrocytes in the skin or marked hemosiderin deposition. ${ }^{2}$ Five different clinical types of PPD have been described, with different clinical appearances, but similar histopathology. They are: progressive pigmented purpuric dermatosis or Schamberg disease (SD), purpura annularis telangiectodes or Majocchi's disease (MD), lichen aureus (LA), pigmented purpuric lichenoid dermatosis, and eczematid-like purpura of Doucas and Kapetanakis. Several other types have also been reported, but they are rare, such as linear, granulomatous, quadrantic, transitory, and familial forms. ${ }^{2}$
The aetiology of PPD is unknown. Venous hypertension, exercise, gravitational dependency, capillary fragility, focal infections, and chemical ingestion are important cofactors. ${ }^{2-4}$ Specific drugs are suspected to induce PPD, including: acetaminophen, aspirin, adalin, carbromal, chlordiazepoxide, glipizide, glybuzole, hydralazine, meprobamate, persantin, reserpine, thiamine, interferon alpha, and medroxyprogesterone acetate injection. ${ }^{2}$ The differential diagnosis of PPD includes hyperglobulinaemic purpura, early mycosis fungoides, purpuric clothing dermatitis, stasis pigmentation, scurvy, leukocytoclastic vasculitis, and drug hypersensitivity reactions. $^{2}$

Laboratory investigations are unremarkable in PPD. A full blood count and peripheral blood smear are necessary to exclude thrombocytopenia. A coagulation screen, bleeding time, platelet ag-

Received on 12.05.2015.

Approved by the Advisory Board and accepted for publication on 10.10.2015.

* Work perfomed at the Medical Faculty (Dermatoveneorology Department) - Bezmialem Vakif University - İstanbul, Turkey. None

Conflict of interest: None

Financial support:

\footnotetext{
Bezmialem Vakif University Medical Faculty - Fatih, Istanbul.

Istanbul University, Cerrahpasa Medical Faculty - Fatih, Istanbul.
}

(C2016 by Anais Brasileiros de Dermatologia 
gregation, capillary test excludes other possible causes of purpura, and tests for, antinuclear antibodies (ANA), rheumatoid factor (RF), anti-HBsAg antibody and anti-HCV antibody should also be performed for excluding rheumatologic diseases and viral infections. ${ }^{1,2}$

Dermatoscopy is a non-invasive, diagnostic technique that allows the visualisation of morphological features invisible to the naked eye; it combines a method that renders the corneal layer of the skin translucent with an optical system that magnifies the image projected onto the retina. ${ }^{5}$ Dermatoscopy has become a routine technique in dermatological practice in the last decade and has contributed to our improved knowledge of the morphology of numerous cutaneous lesions.

A diagnosis of PPD is based on clinical and histopathological features. In this study, we investigate the dermatoscopic findings of PPD.

\section{METHODS}

This study enrolled patients diagnosed with PPD histopathologically who had dermatoscopic records. We reviewed the dermatoscopic images of PPD patients who attended the outpatient clinic in the Istanbul Dermatovenereology Department at the Bezmialem Vakıf University Medical Faculty. The dermatoscopic features of patients were examined using a FotoFinder 2 computerised dermatoscope (FotoFinder systems; Bayern, Germany).

Age, gender, PPD type, cholesterol, triglycerides, low-density lipoproteins (LDL), and dermatoscopic findings were obtained from the patients' records.

\section{RESULTS}

This study enrolled 15 women (47\%) and 17 men (53\%). Ages ranged from 16 to 75 years (median 49.5, mean $45.7 \pm 16.2$ ). Disease duration ranged from 2 to 120 months (median 12, mean $22.1 \pm 24.1$ ). Twenty-nine patients $(91 \%)$ were diagnosed with SD, two $(6 \%)$ with MD, and one (3\%) as linear. Seventeen patients $(61 \%)$ had high LDL, 10 patients (43\%) had hypertriglyceridaemia, while twelve patients (44\%) had hypercholesterolaemia. Dermatoscopy showed: coppery-red pigmentation $(97 \%, \mathrm{n}=31)$ in the background, a brown network $(34 \%, \mathrm{n}=11)$, linear vessels $(22 \%, \mathrm{n}=7)$, round to oval red dots, globules, and patches $(69 \%, \mathrm{n}=22,75 \%, \mathrm{n}=24,34 \%$, $\mathrm{n}=11$, respectively), brown globules (Figure 3$)(26 \%, \mathrm{n}=8)$ and dots $(53 \%, \mathrm{n}=17)$, linear brown lines $(22 \%, \mathrm{n}=7)$, and follicular openings $(13 \%, \mathrm{n}=4)$ (Figures 1 to 3 ; Table 1 ).

LDL levels were high in 17 patients $(61 \%)$ and normal in 11 (39\%). Triglyceride levels were high in $10(43 \%)$ and normal in 13 (57\%). Total cholesterol levels were high in 12 (44\%) and normal in 15 (56\%). The normal levels for LDL, triglyceride, and cholesterol were $<130 \mathrm{mg} / \mathrm{dL},<150 \mathrm{mg} / \mathrm{dL}$ and $<200 \mathrm{mg} / \mathrm{dL}$, respectively.

\section{DISCUSSION}

PPD is a chronic, relapsing disorder of unknown aetiology characterised by a symmetrical rash of petechial and pigmented macules, which is often confined to the lower limbs. It manifests as extravasations of erythrocytes in the skin or marked hemosiderin depositions. ${ }^{2,3}$ It is divided into five clinical types: SD accounts for more than half of all PPD cases, while eczematid-like purpura of Doucas and Kapetanakis, lichen aureus, Majocchi's disease, and pigmented purpuric lichenoid dermatosis are seen in 10\%, 10\%, 5\%, and $5 \%$ of cases, respectively. ${ }^{6,7}$ In our study, SD accounted for $93 \%$ of the cases. This is higher than reported but similar to the results of Gönül et al. (83.3\%), another Turkish study. ${ }^{7}$ Genetic and geographic

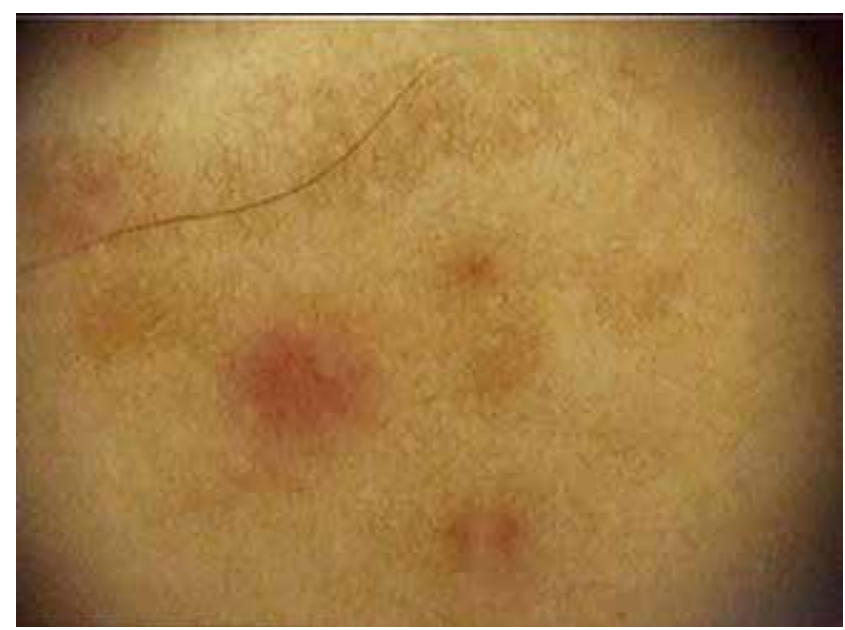

FIGURE 1: Red patch, reticular network
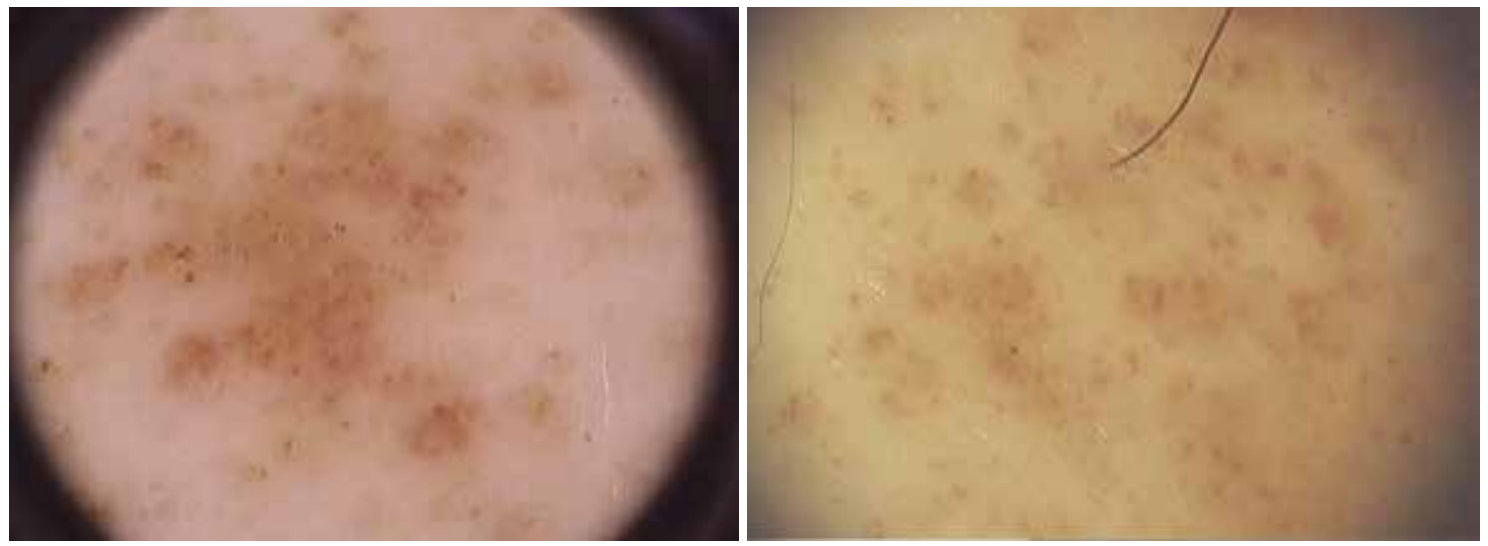

Figure 2: A.

Coppery-red basement, brown, red dots; B. Coppery-red basement, brown, red dots 


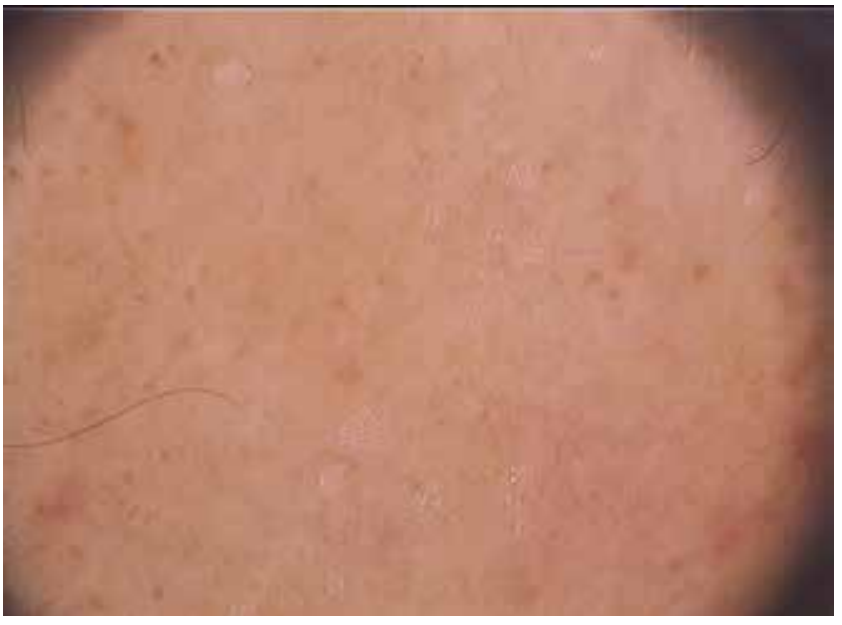

FigURE 3: Linear brown lines, brown globules

TABLE 1: Dermatoscopic findings of pigmented purpuric dermatosis

\begin{tabular}{llll}
\hline \multirow{2}{*}{ Coppery-red pigmentation } & & $\mathbf{n}$ & $\%$ \\
\cline { 2 - 3 } Red globules & $(-)$ & 1 & $3 \%$ \\
& $(+)$ & 31 & $97 \%$ \\
Red dots & $(-)$ & 8 & $25 \%$ \\
& $(+)$ & 24 & $75 \%$ \\
Brown dots & $(-)$ & 10 & $31 \%$ \\
\multirow{3}{*}{ Reticular network } & $(+)$ & 22 & $69 \%$ \\
\multirow{3}{*}{ Red patch } & $(-)$ & 15 & $47 \%$ \\
\multirow{3}{*}{ Brown globules } & $(+)$ & 17 & $53 \%$ \\
& $(-)$ & 21 & $66 \%$ \\
Linear vessels & $(+)$ & 11 & $34 \%$ \\
& $(-)$ & 21 & $66 \%$ \\
Linear lines & $(+)$ & 11 & $34 \%$ \\
& $(-)$ & 23 & $74 \%$ \\
Follicular openings & $(+)$ & 8 & $26 \%$ \\
& $(-)$ & 25 & $78 \%$ \\
& $(+)$ & 7 & $22 \%$ \\
& $(-)$ & 25 & $78 \%$ \\
& $(+)$ & 7 & $22 \%$ \\
& $(-)$ & 27 & $87 \%$ \\
& $(+)$ & 4 & $13 \%$ \\
\hline
\end{tabular}

differences may affect the clinical types, while other types may not be considered or diagnosed as PPD at primary care clinics.

The male to female ratio varies, but the condition is more common in males, except for MD. ${ }^{7}$ In our study, the proportion of males was slightly higher than that of women - 17 men (53\%) and 15 women $(47 \%)$.

While PPD may occur at any age, it is seen most commonly in the fourth and fifth decades of life. ${ }^{1,89}$ In our series, the patients' ages ranged from 16 to 75 years (median 49.5 , mean $45.7 \pm 16.2$ ), similar to the literature.
The aetiology of PPD is unknown. It has been reported that venous hypertension, exercise, gravitational dependency, capillary fragility, focal infections, and alcohol ingestion are important factors in PPD. ${ }^{1,2,7,10}$ Some case series have analysed the granulomatous variant of PPD associated with hyperlipidaemia. ${ }^{7,10,11}$ In one study, $42.9 \%$ of the patients had hypercholesterolaemia, $23.8 \%$ had hypertriglyceridaemia, and $62 \%$ had increased LDL. ${ }^{7}$ In our study, LDL levels were increased in 17 patients $(61 \%)$, hypertriglyceridemia was seen in 10 (43\%), while hypercholesterolaemia was seen in 12 $(44 \%)$. The rates of hypercholestraemia and increased LDL levels in our study were higher than the levels in Turkish adults, whose prevalence rates for hypercholesterolaemia, hypertriglyseridaemia, and increased LDL levels were $38.6 \%, 51.3 \%$, and $30.9 \%$, respectively.,12 Hyperlipidaemia may have been responsible for the microvascular reaction and may play a role in the etiology of PPD.

Dermatoscopy or epiluminescence microscopy is a non-invasive procedure for evaluating coloured lesions of the skin surface. There have been many investigations of melanocytic lesions, especially melanoma. Dermatoscopy can also be used in other areas of dermatology. ${ }^{13}$ In this study, we evaluated the dermatoscopy findings in PPD.

The most common finding was coppery-red pigmentation $(97 \%, \mathrm{n}=31)$. This coppery-red background may be explained by the dermal infiltration of lymphocytes and histiocytes via the extravasation of red blood cells and by hemosiderin in the histiocytes. ${ }^{14}$

In the algorithm used to diagnose pigmented skin lesions by dermatoscopy, a pigment network is used to differentiate between melanocytic and non-melanocytic skin lesions. ${ }^{13,15}$ The presence of a pigment network usually indicates a melanocytic lesion $[13,15,16]$, but it can also be found in a variety of non-melanocytic lesions, including dermatofibroma, solar lentigo and its variants, ink-spot lentigo, seborrheic keratosis, accessory nipples, cutaneous mastocytosis, and normal skin..$^{13,15-18}$ The pigment network corresponds histologically to the presence of melanin in the basal layer of the epidermis. ${ }^{19}$ The pigment network observed in our cases may correspond to hyperpigmentation of the basal cell layer and incontinentia pigmenti in the upper dermis. ${ }^{14}$

The red dots, globules, and patches correspond histopathologically to the extravasation of red blood cells and an increased number of blood vessels, some of which are dilated and swollen. ${ }^{14}$ Dotted vessels are visible in Spitz nevi, melanoma, and inflammatory lesions; while glomerular vessels can be observed in Bowen's disease and stasis dermatitis. Furthermore, dotted vessels appear in psoriasis and viral warts; linear vessels are noticeable in lichen planus. ${ }^{5}$

Brown globules and dots may result from the spherical or elliptical arrangement of melanocytes or melanophages at the dermo-epidermal junction. ${ }^{20}$

Portela et al. examined a lichen aureus patient using dermatoscopy and observed coppery-red pigmentation in the background, permeated by a dark brown network and linear vessels in the central portion of the lesion, accompanied by punctate vessels and a peculiar circular conformation, especially at the periphery of the lesion. ${ }^{21}$ Zaballos et al. described the dermatoscopy of three lichen aureus patients and their findings were similar, entailing a cop- 
pery-red background, round to oval red dots, globules and patches, grey dots, and a partial network of interconnected pigmented lines. ${ }^{14}$ In our study, the majority of cases were SD, and the most significant findings were coppery-red pigmentation in the background $(97 \%)$, red globules $(75 \%)$, red dots $(69 \%)$, brown dots $(53 \%)$, and a reticular network (34\%).

\section{CONCLUSION}

To our knowledge, this is the first study to report the dermatoscopy of PPD. In our opinion, dermatoscopy can be useful in the diagnosis of PPD.D

\section{REFERENCES}

1. Ehsani AH, Ghodsi SZ, Nourmohammad-Pour P, Aghazadeh N, Damavandi MR. Pigmented purpura dermatosis and viral hepatitis: A case control study. Australas J Dermatol. 2013;54:225-7.

2. Sardana K, Sarkar R, Sehgal VN. Pigmented purpuric dermatoses: An overview. Int J Dermatol. 2004;43:482-8.

3. Newton RC, Raimer SS. Pigmented purpuric eruptions. Dermatol Clin. 1985;3:1659.

4. Taketuchi $\mathrm{Y}$, Chinen T, Ichikawa $\mathrm{Y}$, Ito M. Two cases of unilateral pigmented purpuric dermatosis. J Dermatol. 2001;28:493-8.

5. Martín JM, Bella-Navarro R, Jordá E. Vascular patterns in dermatoscopy. Actas Dermosifiliogr. 2012;103:357-75

6. Burns T, Breathnach S, Cox N, Griffiths C, editors. Rook's Textbook of Dermatology. 8th ed. Chichester, West Sussex, UK: Wiley-Blackwell Publishing; 2010. Chapter 49, Purpura and microvascular occlusion; p.22-26

7. Gönül M, Külcü Çakmak S, Ozcan N, Oğuz ID, Gül U, Bıyıklı Z. Clinical and laboratory findings of pigmented purpuric dermatoses. Ann Dermatol. 2014;26:610-4.

8. Sharma L, Gupta S. Clinicoepidemiological study of pigmented purpuric dermatoses. Indian Dermatol Online J. 2012;3:17-20.

9. Engin B, Ozdemir M, Kaplan M, Mevlitoğlu I. Patch test results in patients with pigmented purpuric dermatosis. J Eur Acad Dermatol Venereol. 2009;23:209.

10. Lin WL, Kuo TT, Shih PY, Lin WC, Wong WR, Hong HS. Granulomatous variant of pigmented purpuric dermatoses: report of four new cases and association with hyperlipidaemia. Clin Exp Dermatol. 2007;32:513-5.

11. Wong WR, Kuo TT, Chen MJ, Chan HL. Granulomatous variant of chronic pigmented purpuric dermatosis: report of two cases. Br J Dermatol. 2001;145:162-4.

12. Onat $A$, Türkmen $S$, Karabulut A, Yazıcı M, Can G, Sansoy V. Combined hypercholesterolemia and hypertension among Turkish adults: prevalence and prediction of cardiovascular disease risk. Turk Kardiyol Dern Arş. 2004;32:273278

13. Akay BN, Kittler H, Sanli H, Harmankaya K, Anadolu R. Dermatoscopic findings of cutaneous mastocytosis. Dermatology. 2009;218:226-30.

14. Zaballos P, Puig S, Malvehy J. Dermoscopy of pigmented purpuric dermatoses (lichen aureus): A useful tool for clinical diagnosis. Arch Dermatol. 2004;140:1290-1.

15. Argenziano G, Soyer HP, Chimenti S, Talamini R, Corona R, Sera F, et al. Dermatoscopy of pigmented skin lesions: results of consensus meeting via the Internet. J Am Acad Dermatol. 2003;48:679-93.
16. Yadav S, Vossaert KA, Kopf AW, Silverman M, Grin-Jorgensen C. Histopathologic correlates of structures seen on dermoscopy (epiluminescence microscopy). Am J Dermatopathol. 1993;15:297-305.

17. Argenziano G, Soyer HP, De Giorgi V, Piccolo D, Carli P, Delfino M, et al. Interactive Atlas of Dermoscopy. Milan: EDRA Medical Publishing \& New Media 2000; $p$. 297-305.

18. Arpaia N, Cassano N, Vena GA. Dermatofibroma: a case report and personal considerations. Dermatol Surg. 2004;30:421.

19. Arpaia N, Cassano N, Vena GA. Lessons on dermoscopy: Pigment network in nonmelanocytic lesions. Dermatol Surg. 2004;30:929-30.

20. de Giorgi V, Stante M, Massi D, Mavilia L, Cappugi P, Carli P. Possible histopathologic correlates of dermoscopic features in pigmented melanocytic lesions identified by means of optical coherence tomography. Exp Dermatol. 2005;14:56-9.

21. Portela PS, Melo DF, Ormiga P, Oliveira FJ, Freitas NC, Bastos Júnior CS Dermoscopy of lichen aureus. An Bras Dermatol. 2013;88:253-5.

\author{
MAILING ADDRESS: \\ Dilek Biyik Ozkaya \\ Adnan Menderes Bulv. \\ Fatih \\ Istanbul 34093 \\ E-mail: dilekozkaya@gmail.com
}

How to cite this article: Ozkaya DB, Emiroglu N, Su O, Cengiz FP, Bahali AG, Yildiz P, Demirkesen C, Onsun N. Dermatoscopic findings of pigmented purpuric dermatosis. An Bras Dermatol. 2016;91(5):584-7. 